\title{
Satisfaction survey among primary health care outpatients in the backward region: an empirical study from rural Western China
}

This article was published in the following Dove Press journal:

Patient Preference and Adherence

Xin $\mathrm{He}^{1}$

Lingui $\mathrm{Li}^{2}$

Ying Bian'

'State Key Laboratory of Quality Research in Chinese Medicine, Institute of Chinese Medical Sciences, University of Macau, Taipa, Macau SAR, China; ${ }^{2}$ School of Public Health and Management, Ningxia Medical University, Yinchuan, China
Correspondence: Ying Bian Institute of Chinese Medical Sciences, University of Macau, Avenida da Universidade, Room 2055, N22 Building,

Taipa, Macau SAR, China

Tel +868536520 5586

Email bianying@umac.mo
Background: With a growing health demand, patient satisfaction analysis is essential for evaluating the accessibility and performance of medical services. Previous studies had explored the Chinese outpatient satisfaction and influencing factors in developed areas and tertiary hospitals. Considering the lower education level, less income, and heavier economic burden, it was necessary to conduct a region-specific questionnaire survey for the outpatient's satisfaction in rural Western China.

Objective: To analyze the satisfaction of primary outpatient service in rural Western China, and explore the factors affecting outpatients' satisfaction.

Methods: Questionnaire composed of nine 5-Likert items was applied to survey outpatient satisfaction among randomly selected samples in 11 provinces of Western China. Exploratory factor analysis (EFA) was conducted to study the factor structure of questionnaire. Stepwise multiple linear regression analysis was performed to study the influencing factors.

Results: A total of 2,754 outpatients completed the questionnaire, the response rate was $88.7 \%$. Respondents were most satisfied with medical staff service attitude (3.71 \pm 0.83$)$ and least satisfied with medical cost (2.97 \pm 0.83$)$. A 3-factor solution was adopted in EFA to explain the overall satisfaction. Factors identified were "Service attitude", "Facility and professional skills", and "Patients' cost". And, the questionnaire was proved to have good reliability and acceptable internal consistency. The stepwise multiple linear regression analysis results presented that factors, including sample hospital type $(P<0.05)$, age $(P<0.001)$, education level $(P<0.05)$, occupation $(P<0.01)$, monthly income $(P<0.05)$, and chronic disease conditions $(P<0.01)$ were significantly associated with the dimensional or overall satisfaction.

Conclusion: The primary health care outpatient satisfaction in rural Western China is lower than developed areas and tertiary hospitals. Care providers in backward regions should pay more attention to patients' demographic characteristics and health status, to meet outpatients' actual demand. Efficient hospital management methods, modern technology, and staff training are needed to improve the service quality and care efficiency.

Keywords: outpatient satisfaction, factor analysis, stepwise multiple linear regression, countylevel hospitals, backward regions, Western China

\section{Introduction}

Patient satisfaction is consumers' evaluation about the effectiveness, safety, and benefit of health care service, which is a combination of patients' experience and perception. ${ }^{1-3}$ Patient satisfaction is an important and commonly used indicator for measuring the quality of health care, and higher patient satisfaction would lead to better clinical outcomes and less care resource utilization. Therefore, patient satisfaction survey is essential for patients, health care provider, and health care payer. ${ }^{4-6}$ 
Most patient satisfaction studies were conducted in the USA and European countries, suggesting that patients in the flourishing regions tend to evaluate the quality of health care service based on waiting time, medical staffs' proficiency, hospital environment, and participation in the medical decision making. ${ }^{3,4,7-10}$ There are several recent patient assessment studies, which were conducted in developing countries, including India, Thailand, Tanzania, and Ethiopia. Patients in these countries care more about the location of health facility, hospital comfort, and access to appropriate services. ${ }^{11-15}$ Patients perception varies according to education level, age, income, and residence. ${ }^{15}$

As proposed in previous literature, ${ }^{16}$ with the increasing population and patient expectation, patient satisfaction analysis is essential to evaluate the accessibility and quality of medical service, especially in developing countries, such as China. Some researchers had explored the outpatient satisfaction and factors affecting Chinese patients' satisfaction, mostly from developed provinces or tertiary hospitals, performing descriptive analysis and satisfaction ratings survey. ${ }^{17,18}$ Questionnaire is a commonly used satisfaction survey instrument. As reported in studies conducting univariate or regression analysis, factors, including hospital environment, medical facility, service attitude, patients' involvement in decision making, doctors and nurses' proficient skills, effective communication between patients and doctors, disease severity, medical cost, waiting time, and service time were associated with Chinese outpatients' satisfaction in advanced areas or tertiary hospitals. ${ }^{19-23}$ Similar results were also previously demonstrated in Hong Kong and Taiwan studies. ${ }^{24-26}$

According to Grossman (1973), ${ }^{27}$ patients' demand for medical services is associated with demographic characteristics and socioeconomic conditions; therefore, patients' demand and satisfaction in backward areas should be measured in a different way from developed areas. ${ }^{28}$ So far, no questionnaire studies have been designed to assess primary health care outpatient's satisfaction with a largesample evidence covering different backward provinces in China. Considering the relatively lower education level, less individual income, and heavier economic burden, it is necessary to process a region-specific questionnaire survey for the outpatient's satisfaction in rural Western China. Consequently, the objective of this study was to conduct a satisfaction survey in primary outpatient service in rural Western China and explore the factors affecting outpatients' satisfaction.

\section{Materials and methods}

This research was approved by the research ethics committee of Institute of Chinese Medical Sciences, University of Macau.

\section{Questionnaire development}

The initial questionnaire draft was designed based on the literature review, and the literature search was conducted using CNKI and PubMed database in June 2014, by keywords including "outpatient", "satisfaction", "China" and "questionnaire". More than 50 previous outpatients' satisfaction survey and relevant studies were screened, and the adaptive information was extracted to compose the item pool. And, local medical price, reimbursement percentage, residents' income, and education level were considered during the pilot study. According to the pilot study results and local physicians' advice, the final draft version contains 9 items, including time spent in commuting to hospital, waiting time, doctors' disease description, patients' participation in decision making, staff service attitude, hospital facility, hospital environment, medical cost, and doctors and nurses' professional skills. Interviewees were also asked to fill their background information, including age, gender, occupation, education level, monthly income, medical insurance type, and condition of chronic diseases.

The questionnaire was designed as a 5-point Likert scale, ${ }^{29}$ and interviewees were asked to rate each item: very dissatisfied (1), dissatisfied (2), neither satisfied nor dissatisfied (3), satisfied (4), and very satisfied (5).

\section{Sampling}

Eleven provincial-level divisions in Western China were selected to explore the outpatient satisfaction, including Ningxia Hui Autonomous Region, Guangxi Zhuang Autonomous Region, Xinjiang Weiwuer Autonomous Region, Gansu Province, Shaanxi province, Qinghai province, Sichuan province, Guizhou Province, Yunnan Province, Inner Mongolia, and Tibet Autonomous Region. In each province, all counties were divided into 3 levels by GDP per capita, and 1 sample county was randomly selected from each level of 11 provinces. The county general hospital, maternal and child health center, and hospital of Traditional Chinese Medicine in each sample county were recruited as sample hospitals. Fifty outpatients drawn randomly from each sample hospital were enrolled into the study, receiving the questionnaire when leaving the hospital. Written informed consent was obtained from all interviewees before filling the questionnaire. All questions were explained by trained investigators. 
The questionnaire for interviewees aged $<14$ years was answered by their adult supervisor.

\section{Statistical analysis}

The missing item and total response rates were used to assess the questionnaire acceptability and feasibility. Descriptive data were tabulated to present participants' demographic and other background characteristics. Exploratory factor analysis (EFA), using principal component analysis and varimax rotation, was conducted to assess the dimensionality of overall satisfaction, evaluate the structure validity, and reduce the number of variables. ${ }^{30-32}$ Multiple linear regression analysis in a stepwise method ( $p$ for removal was set at 0.1 and $p$ for entry at 0.05 ) was implied to explore the association between outpatients' characteristics and satisfaction factor scores. Outpatients' background characteristics that showed significant difference in univariate analysis were included as independent variables, with dimensional and overall factor scores as dependent variables.

All data analysis was performed using SPSS version 19.0.

\section{Results}

The questionnaire survey was conducted from October to December 2014. A total of 3,193 patients participated in the survey, and 2,754 questionnaires were fully completed. The missing value rate for each item was $0.2 \%-0.5 \%$, and the total response rate was $88.7 \%$, indicating that the questionnaire was acceptable and feasible.

\section{Descriptive findings}

The descriptive results of participants' demographic and other background characteristics are presented in Table 1. The mean age of respondents was $36.86(\mathrm{SD}=14.30), 40 \%$ were female, and $60 \%$ were male. Only $40 \%$ of interviewees had completed at least high school education. Farming was the most common occupation, and $70.4 \%$ of responders' income was $<2001$ yuan ( $~ 330$ USD) per month. Most participants were enrolled in public medical insurance, $14.6 \%$ of respondents were insured by Urban Employee Basic Medical Insurance (UEBMI), 9.5\% by Urban Resident Basic Medical Insurance (URBMI), and $60.2 \%$ by New Rural Cooperative Medical Scheme (NRCMS). A total of $20 \%$ of the participants had chronic diseases.

\section{Outpatients satisfaction item scores}

The results of the outpatients' satisfaction survey are shown in detail in Table 2. According to the mean scores, respondents were most satisfied with medical staff service
Table I Respondents' characteristics and descriptive findings

\begin{tabular}{|c|c|}
\hline Characteristics & $\mathbf{N}(\%)$ \\
\hline Age, mean $( \pm S D)$ & $36.86( \pm 14.30)$ \\
\hline \multicolumn{2}{|l|}{ Gender } \\
\hline Female & $\mathrm{I}, 10 \mathrm{I}(40.0)$ \\
\hline Male & $\mathrm{I}, 653(60.0)$ \\
\hline \multicolumn{2}{|l|}{ Education } \\
\hline Illiteracy & $287(10.4)$ \\
\hline Primary school & $503(18.3)$ \\
\hline Junior high school & $887(32.2)$ \\
\hline High school & $638(23.2)$ \\
\hline College or above & $439(15.9)$ \\
\hline \multicolumn{2}{|l|}{ Occupation } \\
\hline Farmer & $923(33.5)$ \\
\hline Blue-collar worker & $328(11.9)$ \\
\hline Business/service/enterprise employee & $474(17.2)$ \\
\hline Teacher/governments or public-sector staff & $295(10.7)$ \\
\hline Student/unemployed/other jobs & $679(24.7)$ \\
\hline Retirement & $55(2.0)$ \\
\hline \multicolumn{2}{|l|}{ Monthly income (RMB) } \\
\hline No income & $689(25.0)$ \\
\hline $\mathrm{I}-2,000$ yuan & $\mathrm{I}, 250(45.4)$ \\
\hline $2,00 \mathrm{I}-4,000$ yuan & $655(23.8)$ \\
\hline $4,00 \mathrm{I}$ yuan and above & $160(5.8)$ \\
\hline \multicolumn{2}{|l|}{ Medical insurance } \\
\hline National health insurance & $96(3.5)$ \\
\hline UEBMI & $402(14.6)$ \\
\hline URBMI & $261(9.5)$ \\
\hline NRCMS & $\mathrm{I}, 658(60.2)$ \\
\hline Urban and rural residents medical insurance & $73(2.7)$ \\
\hline Other insurances & $53(1.9)$ \\
\hline No medical insurance & $211(7.7)$ \\
\hline \multicolumn{2}{|l|}{ Chronic diseases } \\
\hline Yes & $550(20.0)$ \\
\hline No & $2,204(80.0)$ \\
\hline
\end{tabular}

Abbreviations: UEBMI, Urban Employee Basic Medical Insurance; URBMI, Urban Resident Basic Medical Insurance; NRCMS, New Rural Cooperative Medical Scheme.

attitude (3.71 \pm 0.83 ) and second, doctors' disease description (3.64 \pm 0.84$)$. Medical cost was the least satisfactory item (2.97 \pm 0.83$)$. The sum of mean scores of 9 items was 30.58 , with the maximum score of 45 , which was relatively lower than the average satisfaction scores in previous studies.

\section{Factor analysis}

EFA was conducted to explore the dimensionality of the overall outpatients' satisfaction in rural Western China and analyze the validity of the dimensional structure.

The overall Cronbach's $\alpha$ value was 0.75 , suggesting good reliability. The Kaiser-Meyer-Olkin measure for the dataset was 0.804, the Bartlett's test was 6,002.289 $(P<0.001)$, and all item-total correlations exceeded 0.50, implying that the data were adequate for EFA. ${ }^{31-33}$

Principal component analysis and varimax rotation were adopted. As shown in Table 3, only 2 factors had 
Table 2 Outpatients satisfaction item scores

\begin{tabular}{|c|c|c|c|c|c|c|c|}
\hline & Contents & $\begin{array}{l}\text { Very } \\
\text { dissatisfied, } \\
\text { N (\%) }\end{array}$ & $\begin{array}{l}\text { Dissatisfied, } \\
\text { N (\%) }\end{array}$ & $\begin{array}{l}\text { Neither satisfied } \\
\text { nor dissatisfied, } \\
\text { N (\%) }\end{array}$ & $\begin{array}{l}\text { Satisfied, } \\
\text { N (\%) }\end{array}$ & $\begin{array}{l}\text { Very } \\
\text { satisfied, } \\
\mathbf{N}(\%)\end{array}$ & Mean \pm SD \\
\hline$x_{1}$ & Time spent commuting to hospital & II $4(4.1)$ & $37 \mid(13.5)$ & $\mathrm{I}, 217(44.2)$ & $774(28.1)$ & $278(10.1)$ & $3.27 \pm 0.96$ \\
\hline $\mathrm{X}_{2}$ & Waiting time & $169(6.1)$ & $559(20.3)$ & $1,249(45.4)$ & $584(21.2)$ & $193(7.0)$ & $3.03 \pm 0.97$ \\
\hline $\mathrm{X}_{3}$ & Doctors' disease description & $42(1.5)$ & $117(4.2)$ & $\mathrm{I}, 038(37.7)$ & $\mathrm{I}, 153(41.9)$ & $404(14.7)$ & $3.64 \pm 0.84$ \\
\hline $\mathrm{X}_{4}$ & Patients' participation in decision-making & $93(3.4)$ & $127(4.6)$ & $1,016(36.9)$ & I, $155(4 \mid .9)$ & $363(13.2)$ & $3.57 \pm 0.90$ \\
\hline$X_{5}$ & Service attitude & $32(1.2)$ & $113(4.1)$ & $938(34.1)$ & $1,209(43.9)$ & $462(16.8)$ & $3.7 I \pm 0.83$ \\
\hline$x_{6}$ & Hospital facility & $32(1.2)$ & $216(7.8)$ & $\mathrm{I}, 367(49.6)$ & $879(31.9)$ & $260(9.4)$ & $3.4 I \pm 0.8 I$ \\
\hline$x_{7}$ & Hospital environment & $48(1.7)$ & $272(9.9)$ & $|, 32|(48.0)$ & $885(32.1)$ & $228(8.3)$ & $3.35 \pm 0.84$ \\
\hline $\mathrm{X}_{8}$ & Medical cost & $87(3.2)$ & $605(22.0)$ & $\mathrm{I}, 479(53.7)$ & $457(16.6)$ & $126(4.6)$ & $2.97 \pm 0.83$ \\
\hline$x_{9}$ & Doctors and nurses' professional skills & $19(0.7)$ & $90(3.3)$ & $\mathrm{I}, 083(39.3)$ & $\mathrm{I}, 276(46.3)$ & $286(10.4)$ & $3.62 \pm 0.84$ \\
\hline
\end{tabular}

eigenvalues $>1 .{ }^{34}$ However, combined with the cumulative variance percentage and scree plot (see Figure 1), ${ }^{35,36}$ a 3-factor solution was applied in the factor analysis.

According to the factor loading values, 9 items were explained by 3 dimensions. Factor 1 "Service attitude" consisted of the 3 items of the questionnaire, including patients' participation in decision making, doctors' disease description, and medical staff service attitude. Factor 2 "Facility and professional skills" consisted of hospital environment, hospital facility, and doctors and nurses' professional skills. Factor 3 "Patients' cost" consisted of 3 items, including waiting time, time spent commuting to hospital, and medical cost.

The internal consistency of the matrix was examined. For Factors 1 and 2, the Cronbach's $\alpha$ values were 0.733 and 0.740 , respectively, which were considered very good. The inter-item correlation (IIC) can also be adopted as a measure of internal consistency when the number of items in the scale was $<10$, which was acceptable between 0.2 and 0.4. Thus, the internal consistency of Factor 3 was considered acceptable although the Cronbach's $\alpha$ value was only $0.542 .{ }^{32,37}$

More details of EFA results are available in Table 4.

\section{Factors associated with outpatient's satisfaction}

The regression method was used to estimate the factor score coefficients, and the scores of Factor $1\left(\mathrm{~F}_{1}\right)$, Factor $2\left(\mathrm{~F}_{2}\right)$, and Factor $3\left(\mathrm{~F}_{3}\right)$ were produced by SPSS software. To comprehensively explore the characteristics associated with outpatients' satisfaction, the factor score of overall satisfaction (F) was calculated based on the score and variance contribution rate of the 3 main factors: $:^{31,38}$

$$
\mathrm{F}=0.22872 * \mathrm{~F}_{1}+0.21113 * \mathrm{~F}_{2}+0.18192 * \mathrm{~F}_{3}
$$

Stepwise multiple linear regression was conducted to investigate the factors influencing the 3 main dimensions and the overall satisfaction. Patients' age, sample hospital type, education, occupation, monthly income, medical insurance type, and chronic disease condition showed significant differences in the univariate analysis, thus included in regression model as independent variables, with $\mathrm{F}_{1}, \mathrm{~F}_{2}, \mathrm{~F}_{3}$ and $\mathrm{F}$ as dependent variables.

Table 5 presents the results of the stepwise multiple linear regression, which demonstrated that the age, sample hospital type, education, occupation, monthly income, and

Table 3 Factor eigenvalues and variance percentage

\begin{tabular}{|c|c|c|c|c|c|c|}
\hline \multirow[t]{2}{*}{ Components } & \multicolumn{3}{|c|}{ Initial eigenvalue } & \multicolumn{3}{|c|}{ Rotation sums of square loadings } \\
\hline & Total & $\%$ of variance & Cumulative \% & Total & $\%$ of variance & Cumulative \% \\
\hline I & 3.243 & 36.038 & 36.038 & 2.058 & 22.872 & 22.872 \\
\hline 2 & $\mathrm{I} .493$ & 16.584 & 52.622 & 1.900 & 21.113 & 43.985 \\
\hline 3 & 0.860 & 9.555 & 62.177 & 1.637 & 18.192 & 62.177 \\
\hline 4 & 0.840 & 9.338 & 71.515 & & & \\
\hline 5 & 0.622 & 6.906 & 78.421 & & & \\
\hline 6 & 0.589 & 6.545 & 84.966 & & & \\
\hline 7 & 0.561 & 6.231 & 91.197 & & & \\
\hline 8 & 0.405 & 4.499 & 95.696 & & & \\
\hline 9 & 0.387 & 4.304 & 100.000 & & & \\
\hline
\end{tabular}




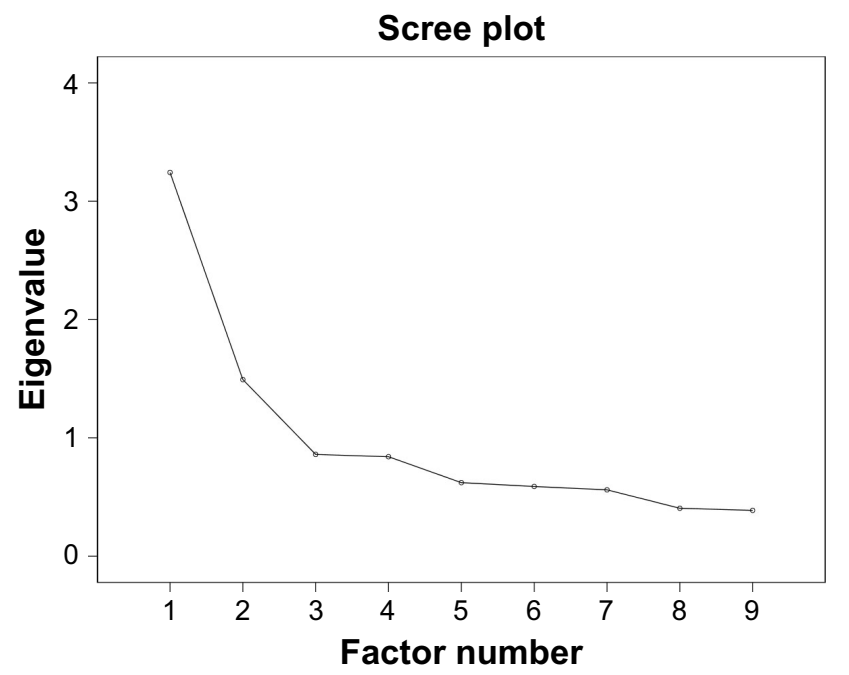

Figure I Scree plot of eigenvalues.

chronic disease condition were statistically associated with the dimensional or overall outpatient satisfaction.

According to the coefficients and $P$-values, significant differences were observed among different respondent populations in dimensional satisfaction: older outpatients had higher satisfaction score in all 3 dimensions; interviewees from general county hospitals were more satisfied with "Facility and professional skills", but less satisfied with other 2 dimensions than other county hospitals; compared with lower educated patients, respondents who had completed at least junior middle school were more satisfied with "Service attitude" and "Facility and professional skills", less satisfied with "Patients' cost"; outpatients with chronic diseases graded higher in "Service attitude" and "Facility and professional skills"; higher income participants were more satisfied with "Patients' cost", and less satisfied with "Service attitude"; and teachers, governments staff, service industry workers, business workers, enterprise employee, and retirees, in comparison with farmers, workers, students, and the unemployed, were more satisfied with "Service attitude".

Different respondent populations also had significant differences in overall satisfaction: the overall satisfaction increased significantly with age; interviewees from other county hospitals were more satisfied than those from general county hospitals; outpatients with chronic diseases graded higher overall satisfaction; and higher educated respondents were more satisfied; teachers, governments staff, service industry workers, business workers, enterprise employees and retirees, compared with farmers, workers, students and the unemployed, were more satisfied with overall outpatient health care.

\section{Discussion}

Patients' satisfaction is an important and commonly used indicator to analyze the patients' demand, performance, and utilization of medical service. Therefore, patients' satisfaction research is essential in the process of China's health system reform. Although several patient satisfaction reports had been published before, no intensive study was conducted to investigate outpatients' satisfaction with large-sample evidence covering China's backward provinces.

In this research, county hospital outpatients' satisfaction of 11 provinces in Western China were analyzed. A total of 2,754 outpatients completed the questionnaire, and the response rate was $88.7 \%$. Among included respondents, 45.5\% were farmers and $60.2 \%$ were insured with the NRCMS. According to China's National Health Service Survey (NHSS) report, $2013,{ }^{39}$ Western China residents have lower outpatient satisfaction rate than Middle and Eastern China. Rural residents have higher satisfaction rate with regard to "medical staff" (80.3\%-82.7\%) than "hospital environment" (67.9\%) and

Table 4 Results of EFA

\begin{tabular}{|c|c|c|c|c|c|c|}
\hline Item & Factors and contents & Loadings & $\mathbf{h}^{2}$ & $\begin{array}{l}\text { Item-total } \\
\text { correlation }\end{array}$ & Cronbach's $\alpha$ & IIC \\
\hline & Service attitude (Factor I) & & & & 0.733 & 0.477 \\
\hline $\mathrm{X}_{4}$ & Patients' participation in decision making & 0.840 & 0.733 & 0.805 & & \\
\hline$X_{3}$ & Doctors' disease description & 0.815 & 0.729 & 0.803 & & \\
\hline \multirow[t]{2}{*}{$X_{5}$} & Staff service attitude & 0.588 & 0.518 & 0.880 & & \\
\hline & Facility and professional skills (Factor 2) & & & & 0.740 & 0.487 \\
\hline$X_{7}$ & Hospital environment & 0.861 & 0.771 & 0.797 & & \\
\hline$X_{6}$ & Hospital facility & 0.824 & 0.748 & 0.794 & & \\
\hline \multirow[t]{2}{*}{$X_{9}$} & Doctors and nurses' professional skills & 0.555 & 0.520 & 0.894 & & \\
\hline & Patients' cost (Factor 3) & & & & 0.542 & 0.279 \\
\hline$X_{2}$ & Waiting time & 0.796 & 0.650 & 0.632 & & \\
\hline$x_{1}$ & Time spent commuting to hospital & 0.750 & 0.572 & 0.652 & & \\
\hline $\mathrm{X}_{8}$ & Medical cost & 0.574 & 0.356 & 0.789 & & \\
\hline
\end{tabular}

Abbreviations: EFA, Exploratory factor analysis; IIC, inter-item correlation. 
Table 5 Multiple linear regression results of factors influencing outpatients' satisfaction

\begin{tabular}{|c|c|c|c|c|c|c|c|c|}
\hline \multirow[t]{2}{*}{ Variable } & \multicolumn{2}{|c|}{$\begin{array}{l}\text { Service attitude } \\
\left(F_{1}\right)\end{array}$} & \multicolumn{2}{|c|}{$\begin{array}{l}\text { Facility and } \\
\text { professional } \\
\text { skills }\left(F_{2}\right)\end{array}$} & \multicolumn{2}{|c|}{$\begin{array}{l}\text { Patients' cost } \\
\left(F_{3}\right)\end{array}$} & \multicolumn{2}{|c|}{$\begin{array}{l}\text { Overall satisfaction } \\
\text { (F) }\end{array}$} \\
\hline & $\beta$ & $P$-value & $\beta$ & $P$-value & $\beta$ & $P$-value & $\beta$ & $P$-value \\
\hline Age & 0.003 & $<0.016^{*}$ & 0.004 & $0.002^{* *}$ & 0.007 & $<0.00 I^{* * *}$ & 0.003 & $<0.001 * * *$ \\
\hline \multicolumn{9}{|l|}{ Sample hospital type } \\
\hline Other county hospitals ${ }^{a}$ & - & - & - & - & - & - & - & - \\
\hline County general hospitals & -0.113 & $0.003^{* *}$ & 0.098 & $0.011^{*}$ & -0.147 & $<0.001 * * *$ & -0.032 & $0.018^{*}$ \\
\hline \multicolumn{9}{|l|}{ Education } \\
\hline Primary school or less ${ }^{a}$ & - & - & - & - & - & - & & \\
\hline Junior middle school or higher & 0.197 & $<0.001 * * *$ & 0.110 & $0.012^{*}$ & -0.145 & $0.00 I^{* *}$ & 0.037 & $0.029 *$ \\
\hline \multicolumn{9}{|l|}{ Occupation } \\
\hline $\begin{array}{l}\text { Farmer/worker/student/ } \\
\text { unemployment/others }\end{array}$ & - & - & - & - & - & - & - & - \\
\hline $\begin{array}{l}\text { Business/service/enterprise employee/ } \\
\text { government staff/teacher/retirement }\end{array}$ & 0.167 & $<0.001 * * *$ & & & & & 0.042 & $0.008 * *$ \\
\hline \multicolumn{9}{|l|}{ Monthly income (RMB) } \\
\hline No income ${ }^{a}$ & - & - & - & - & - & - & - & - \\
\hline $\mathrm{I}-2,000$ yuan & & & & & 0.164 & $<0.001 * * *$ & & \\
\hline 2,001 yuan or above & -0.121 & $0.046^{*}$ & & & 0.140 & $0.008^{* *}$ & & \\
\hline \multicolumn{9}{|l|}{ Chronic diseases } \\
\hline $\mathrm{No}^{\mathrm{a}}$ & - & - & - & - & - & - & - & - \\
\hline Yes & 0.204 & $<0.001 * * *$ & 0.139 & $0.005^{* *}$ & & & 0.074 & $<0.001 * * *$ \\
\hline
\end{tabular}

Notes: ${ }^{*} p<0.05,{ }^{* *} p<0.01,{ }^{* * *} p<0.001$, ${ }^{a}$ As reference category.

"waiting time" (70.7\%), supporting the results of higher satisfaction in "service attitude", "doctors' disease description" and "medical staff proficient skills" in this paper. "Medical cost" was the least satisfactory item, which had also been previously presented in NHSS report and outpatients' satisfaction study in Beijing. ${ }^{23,39}$ In this study, no satisfaction item core exceeded 3.8, less than the overall satisfaction scores (4.67 \pm 0.62$)$ for outpatient in tertiary hospitals, ${ }^{20}$ the result is consistent with previous references, ${ }^{40,41}$ suggesting that outpatients in primary health care in rural Western China were relatively less satisfied with medical service than developed areas or tertiary hospitals.

EFA results showed a 3-dimension structure of overall outpatient satisfaction, "Service attitude", "Facility and professional skills", and "Patients' cost" with 3 items, respectively, and demonstrated acceptable reliability and validity. The stepwise multiple linear regression results indicated that age, sample hospital type, education, occupation, monthly income, and chronic disease condition were statistically associated with dimensional or overall outpatient satisfaction.

The overall satisfaction increased with age, which was agreeable to the report of outpatient satisfaction in Ningxia province and Shanghai. ${ }^{21,42}$ Respondents with chronic diseases tended to have higher overall satisfaction, and a similar trend was observed in satisfaction study from developed areas. ${ }^{23}$ It is possible that the elderly and chronic patients, compared with the young and patients without chronic diseases, were more experienced and trusted their doctors due to their health status. Participants from county-level general hospital were less satisfied with "Patients' cost" than other county hospitals, since waiting time was reported as the most important item of patient satisfaction in general hospitals, ${ }^{43}$ this result was in agreement with the lower overall satisfaction in county general hospital. Outpatients with higher income were more satisfied with "Patient cost" but less satisfied with "Service attitude", predicting the increasing demand for better service attitude with the growing income of Chinese residents. Contrary to previous evidence, ${ }^{44}$ although less satisfied with "Patients' cost", better educated outpatients were more satisfied with "Service attitude", "Facility and professional skills", and overall outpatient service. It is probably the accessibility to high-quality medical service rather than the affordability that influence the overall satisfaction of educated outpatients in rural Western China. Teachers, governments staff, service industry workers, business workers, enterprise employees, and retirees had higher overall satisfaction than farmers, workers, students, and the unemployed, which may be related to the stable income and higher reimbursement rate of the former.

Patient satisfaction is a reflection of the residents' health care demand, understanding the demand of patients under different conditions plays a crucial role in improving the performance and efficiency of medical services. There are 
similarities and differences between the results in this survey and previous literatures, which suggest that outpatients' health care demand in rural Western China have their own uniqueness. As reported in China's NHSS, 2013, "39 "high medical cost" was the primary cause of rural outpatient dissatisfaction in recent years, and then "poor professional skills" and "bad service attitude". However, considering the association between outpatients' characteristics and satisfaction in this study, primary demand of some rural outpatients has altered from lower price to higher efficiency, better service attitude, and professional skills. Since China has implemented the national Essential Medicines List in 2009 and required no drug profit margins in public hospitals in 2017 , a universal access to affordable essential medicines would be promoted in a few years, health care providers should identify and target more initiatives to improve service attitude, environment, and professional skills. In rural Western China, efficient hospital management methods, modern technologies, and more staff training are needed to improve the health care service quality. Implementation of electronic patient record system and consultation desk in each department may reduce the patient queue time and doctor preparation time in general hospitals. ${ }^{45}$ More interpersonal communication training would help doctors and nurses in disease explanation and promoting service attitude. ${ }^{46}$ Rural primary health care institutions are also suggested to develop more patient education about chronic disease management, promote patient participation, and improve the care efficiency. ${ }^{47}$

Most of published satisfaction questionnaire survey on Chinese patients were single-center study in tertiary hospitals or developed regions, ${ }^{23,48}$ conducting regression analysis on mean satisfaction score or satisfaction rate..$^{21,44}$ Compared with previous literature, a questionnaire was developed in this study to collect primary health care outpatients' satisfaction score in rural Western China, then EFA and multiple linear regression were conducted to describe the satisfaction dimension and associated factors, exploring rural outpatient satisfaction from another perspective. It is the first outpatient satisfaction questionnaire study based on EFA with multiprovince evidence in backward China, and the questionnaire showed acceptable reliability and good feasibility.

\section{Limitations}

Although there was a large sample size and reliable results, it should be noted that this study has some limitations: 1) the research sampling was not conducted based on the population distribution of 11 provinces, which may cause the deviation of sample resource. 2) Differences of economic level and medical service quality among 11 provinces were not controlled, by which the satisfaction difference caused could not be explained in this study.

\section{Conclusion}

On the whole, the primary health care outpatient satisfaction in rural Western China is lower than developed areas and tertiary hospitals, "Service attitude", "Facility and professional skills", and "Patients' cost" were the main 3 dimensions of overall satisfaction, with significant differences among patients with different demographic characteristics and chronic disease conditions. Local health care institutions should evaluate and manage the outpatient service quality based on the actual need of patients, considering patients' demographic characteristics and health status. Efficient hospital management methods, modern technologies, and staff training are needed to improve the quality of medical service and care efficiency in backward areas.

\section{Acknowledgment}

This study was supported by the Research Fund of the University of Macau, Macau SAR, China. Funds (MYRG106(Y1-L3)-ICMS13-BY and MYRG2015-00190ICMS-QRCM).

\section{Disclosure}

The authors report no conflicts of interest in this work.

\section{References}

1. Doyle C, Lennox L, Bell D. A systematic review of evidence on the links between patient experience and clinical safety and effectiveness. $B M J$ Open. 2013;3(1):e001570.

2. Williams B. Patient satisfaction: a valid concept? Soc Sci Med. 1994; 38(4):509-516.

3. Tehrani AB, Feldman SR, Camacho FT, Balkrishnan R. Patient Satisfaction with Outpatient Medical Care in the United States. Health Outcomes Res Med. 2011;2(4):e197-e202.

4. Kleefstra SM, Kool RB, Veldkamp CM, et al. A core questionnaire for the assessment of patient satisfaction in academic hospitals in The Netherlands: development and first results in a nationwide study. Qual Saf Health Care. 2010;19(5):e24.

5. Säilä T, Mattila E, Kaila M, Aalto P, Kaunonen M. Measuring patient assessments of the quality of outpatient care: a systematic review. J Eval Clin Pract. 2008;14(1):148-154.

6. Anhang Price R, Elliott MN, Zaslavsky AM, et al. Examining the role of patient experience surveys in measuring health care quality. Med Care Res Rev. 2014;71(5):522-554.

7. Etier BE, Orr SP, Antonetti J, Thomas SB, Theiss SM. Factors impacting Press Ganey patient satisfaction scores in orthopedic surgery spine clinic. Spine J. 2016;16(11):1285-1289.

8. Garratt AM, Bjaertnes ØA, Krogstad U, Gulbrandsen P. The OutPatient Experiences Questionnaire (OPEQ): data quality, reliability, and validity in patients attending 52 Norwegian hospitals. Qual Saf Health Care. 2005;14(6):433-437.

9. Kleefstra SM, Kool RB, Zandbelt LC, de Haes JCJM. An instrument assessing patient satisfaction with day care in hospitals. BMC Health Serv Res. 2012;12:125. 
10. Rahmqvist M, Bara AC. Patient characteristics and quality dimensions related to patient satisfaction. Int J Qual Health Care. 2010; 22(2):86-92.

11. Mohd A, Chakravarty A. Patient satisfaction with services of the outpatient department. Med J Armed Forces India. 2014;70(3):237-242.

12. Goel S, Sharma D, Singh A. Development and validation of a patient satisfaction questionnaire for outpatients attending health centres in North Indian cities. J Health Serv Res Policy. 2014;19(2):85-93.

13. Jaturapatporn D, Hathirat S, Manataweewat B, et al. Reliability and validity of a Thai version of the General Practice Assessment Questionnaire (GPAQ). J Med Assoc Thai. 2006;89(9):1491-1496.

14. Khamis K, Njau B. Patients' level of satisfaction on quality of health care at Mwananyamala hospital in Dar es Salaam, Tanzania. BMC Health Serv Res. 2014;14(1):400.

15. Woldeyohanes TR, Woldehaimanot TE, Kerie MW, Mengistie MA, Yesuf EA. Perceived patient satisfaction with in-patient services at Jimma University Specialized Hospital, Southwest Ethiopia. BMC Res Notes. 2015;8:285.

16. Andaleeb SS. Service quality perceptions and patient satisfaction: a study of hospitals in a developing country. Soc Sci Med. 2001; 52(9):1359-1370.

17. Cai S, Cai W, Deng L, Cai B, Yu M. Hospital organizational environment and staff satisfaction in China: A large-scale survey. Int $J$ Nurs Pract. 2016;22(6):565-573.

18. Li X, Zhang H, Wang J, Li F, Chen J, Chen J. Assessing patient satisfaction with medication related services in hospital settings: a crosssectional questionnaire survey in China. Int $J$ Clin Pharmacol Ther. 2014;52(7):587-597.

19. Lv Y, Xue C, Ge Y, et al. Analysis of factors influencing inpatient and outpatient satisfaction with the Chinese military health service. PLoS One. 2016;11(3):e0151234.

20. Sun J, Hu G, Ma J, et al. Consumer satisfaction with tertiary healthcare in China: findings from the 2015 China National Patient Survey. Int $J$ Qual Health Care. 2017;29(2):213-221.

21. Yu W, Li M, Xue C, et al. Determinants and influencing mechanism of outpatient satisfaction: a survey on tertiary hospitals in the People's Republic of China. Patient Prefer Adherence. 2016;10:601-612.

22. Zhang N, Sun D, Zhou H. Influencing factors of outpatients' satisfaction rate in large general hospitals. Chin Hosp. 2011;15(10):25-27. Chinese.

23. Bao C, Zhou Y, Li J, Wu F, Cao J, Tian J. Investigation and analysis of outpatients' satisfaction of 2170 cases. Chin Hosp Manage. 2015; 35(9):34-36.

24. Stanworth JO, Hsu RS, Warden CA. Validation of a Measure of Chinese Outpatients' Satisfaction in the Taiwan Setting. Inquiry. 2017;54.

25. Wong EL, Leung MC, Cheung AW, Yam CH, Yeoh EK, Griffiths S. A population-based survey using PPE-15: relationship of care aspects to patient satisfaction in Hong Kong. Int J Qual Health Care. 2011; 23(4):390-396.

26. Xie Z, Or C. Associations between waiting times, service times, and patient satisfaction in an endocrinology outpatient department: A time study and questionnaire survey. Inquiry. 2017;54: 46958017739527.

27. Grossman M. On the Concept of Health Capital and the Demand for Health. J Polit Econ. 1972;80(2):223-255.
28. Wei J, Shen L, Yang HB, et al. Development and validation of a Chinese outpatient satisfaction questionnaire: evidence from 46 public general hospitals and 5151 outpatients. Public Health. 2015; 129(11):1523-1529.

29. Likert R. A technique for the measurement of attitudes. Arch Psychol. 1932; 22 140, 55.

30. Alamanou GD, Balokas AS, Fotos VN, Patiraki E, Brokalaki H. Information needs of cancer patients: Validation of the Greek Cassileth's Information Styles Questionnaire. Eur J Oncol Nurs. 2016;20:49-57.

31. Field A. Discovering statistics using IBM SPSS statistics. Carmichael M, editor. London, UK: SAGE Publications Ltd. 2013.

32. Pallant J. SPSS survival manual. UK: McGraw-Hill Education; 2013.

33. Wu M. SPSS operation and application: The practice of auantitative analysis of auestionnaire data. Chongqing University Press; 2010.

34. Kaiser HF. The application of electronic computers to factor analysis. Educ Psychol Meas. 1960;20(1):141-151.

35. Horn JL. A rationale and test for the number of factors in factor analysis. Psychometrika. 1965;30:179-185.

36. Cattell RB. The scree test for the number of factors. Multivariate Behav Res. 1966;1(2):245-276.

37. Mansour M. Factor analysis of nursing students' perception of patient safety education. Nurse Educ Today. 2015;35(1):32-37.

38. Distefano C, Zhu M, Mindrila D. Understanding and using factor scores: Considerations for the applied researcher. Prac Assess, Res Eval. 2009; 14(20):1-11.

39. Center for Health Statistics and Information. An Analysis Report of National Health Services Survey in China, 2013: Beijing Medical University and China Xie - he Medical University Joint Publishing House; 2015. Available from: http://www.nhfpc.gov.cn/ewebeditor/u ploadfile/2016/10/20161026163512679.pdf. Accessed September 14, 2018. Chinese.

40. Chen X. Satisfaction study on rural community healthcare service in backward area. Labor Security World. 2012;10:48-52.

41. Ge Z, Huang J, Wang M, Hu Y, Lv X, Chen Y. Analyzing the outpatients' satisfaction in township health clinics. Chin Health Serv Manage. 2011;2:132-134.

42. Li J, Li Z, Qiao H, Ouyang H. Outpatient satisfaction study in public county hospital reform pilot hospitals, Ningxia province. Ningxia Med Univ. 2016;38(12):1396-1400.

43. Yuan Y, Li L. Investigation and analysis of outpatient satisfaction in a general hospital in Hunan province. China Health Ind. 2015;26:51-53.

44. Zhou Z, Mei C, Zhang Y, Shao J. Study on satisfaction degree of outpatients in a top-notched hospital. Mod Prev Med. 2011;38(7):1262-1265.

45. Middleton B, Bloomrosen M, Dente MA, et al. Enhancing patient safety and quality of care by improving the usability of electronic health record systems: recommendations from AMIA. J Am Med Inform Assoc. 2013;20(e1):e2-e8.

46. Al-Abri R, Al-Balushi A. Patient satisfaction survey as a tool towards quality improvement. Oman Med J. 2014;29(1):3-7.

47. Nie L, Wu H, Wang Y, Yuan X. Analyzing the satisfaction on health management for rural patients with chronic diseases and its influencing factors. Chin Health Serv Manage. 2018;3:205-208.

48. Shi J, Gong Y, Li Y, Jiang Y, Hu P. Development of out-patient satisfaction assessment scale and empirical study. Chin Health Serv Manage. 2015;4:262-267.
Patient Preference and Adherence

\section{Publish your work in this journal}

Patient Preference and Adherence is an international, peer-reviewed, open access journal that focuses on the growing importance of patient preference and adherence throughout the therapeutic continuum. Patient satisfaction, acceptability, quality of life, compliance, persistence and their role in developing new therapeutic modalities and compounds to optimize

\section{Dovepress}

clinical outcomes for existing disease states are major areas of interest for the journal. This journal has been accepted for indexing on PubMed Central. The manuscript management system is completely online and includes a very quick and fair peer-review system, which is all easy to use. Visit http://www dovepress.com/testimonials.php to read real quotes from published authors. 